\section{Tropical Journal of Pathology and \\ Microbiology}

2021 Volume 7 Number 4 July-August

\title{
"The Study of Bacteriological Agents of Chronic Suppurative Otitis Media Aerobic Culture and Antibiotic Sensitivity Testing Pattern at a Tertiary Care Hospital in and around Rajamundry: A cross-sectional study"
}

\author{
Pantagada N. ${ }^{1}$, Kavoori P. ${ }^{2 *}$
}

DOI: https://doi.org/10.17511/jopm.2021.i04.09

\footnotetext{
1 Neelima Pantagada, Assistant Professor, Department of Microbiology, GSL Medical College, Rajahmundry, Andhra Pradesh, India.

2* Praveen Kavoori, Assistant Professor, Department of Microbiology, GSL Medical College, Rajahmundry, Andhra Pradesh, India.
}

Introduction: Chronic suppurative otitis media is a chronic infection of the middle ear and mastoid cavity which if not treated leads to partial or total loss of hearing and even life-threatening complications like meningitis and Intracranial abscess. Hence it is important to treat the persistent ear discharge in CSOM according to the antimicrobial sensitivity of the organism isolated. Methods: This is a prospective cross-sectional study done in 135 clinically diagnosed patients of CSOM at GSL medical college and General Hospital, Rajamundry, Andhra Pradesh from May 2019 to October 2019. Sterile swabs were used to collect pus from discharging ear and were inoculated onto Blood and MacConkey agar for 24-48 hrs, and identification of organisms was done by using standard biochemical reactions and antibiotic sensitivity testing done by using modified Kirby- Bauer method as per CLSI guidelines. Results: A total of 156 strains were isolated from 135 patients in the present study of which Pseudomonas aeruginosa and Staphylococcus aureus were amongst the most isolated pathogens in culture. Imipenem showed the most sensitivity against Pseudomonas, subsequently levofloxacin and piperacillin. Linezolid was the most sensitive versus Staphylococcus ensued by ciprofloxacin and cloxacillin. Conclusions: In the present study of Chronic suppurative otitis media patients, Pseudomonas and Staphylococcus were highly prevalent and showed increased resistance to beta-lactams and commonly used antimicrobial drugs. Antimicrobials like imipenem, piperacillin, and quinolones are effective against most cases of chronic suppurative otitis media.

Keywords: Chronic suppurative otitis media, Aerobic bacterial culture, Antimicrobial sensitivity, Pseudomonas aeruginosa, Staphylococcus aureus

Corresponding Author

Praveen Kavoori, Assistant Professor, Department of Microbiology, GSL Medical College, Rajahmundry, Andhra Pradesh, India.

Email: chanduthegreat2014@gmail.com
How to Cite this Article

To Browse

Neelima Pantagada, Praveen Kavoori, "The Study of Bacteriological Agents of Chronic Suppurative Otitis Media Aerobic Culture and Antibiotic Sensitivity Testing Pattern at a Tertiary Care Hospital in and around Rajamundry: A cross-sectional study". Trop J Pathol Microbiol. 2021;7(4):207-214.

Available From

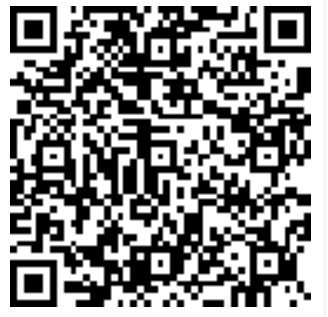

https://pathology.medresearch.in/index.php/jopm/ar ticle/view/552

$\begin{array}{cc}\begin{array}{c}\text { Manuscript Received } \\ \text { 2021-07-28 }\end{array} & \begin{array}{c}\text { Review Round } \mathbf{1} \\ 2021-07-08\end{array} \\ \text { Conflict of Interest } \\ \text { No } & \text { Funding } \\ \text { Nil }\end{array}$

an Open Access article licensed under a Creative Commons Attribution 4.0 International License
https://creativecommons.org/licenses/by/4.0/ unported [CC BY 4.0].

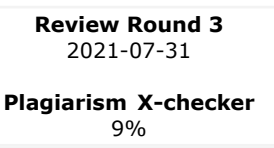

Accepted 2021-08-02

Note 


\section{Introduction}

Any inflammation of the middle ear cleft, regardless of etiology and pathogenesis, is Otitis media. The Eustachian tube, also called the auditory tube, extends from the middle ear to the upper part of the nasopharynx and is responsible for equalizing pressure at both ends, health, removal of secretions and protection against infections. The blockade of the Eustachian tube for any reason would occasionally progress to otitis media. The children are more prone to frequent upper respiratory tract infections that ascend to the middle ear and may subsequently progress to Chronic suppurative otitis media (CSOM) [1]. The difference in the anatomy of the paediatric Eustachian tube favors the creation of stasis of nasopharyngeal secretions making their movement difficult favoring the growth of microorganisms than in adults [2]. The acute form is acute suppurative otitis media usually associated with the infection in the upper respiratory tract whereas persistent form is known as chronic suppurative otitis media [2]. Acute suppurative otitis media is an acute inflammation of the middle ear by pyogenic organisms that is more common especially in infants and children of low socioeconomic groups [3]. Chronic suppurative otitis media is a chronic inflammation of the middle ear and mastoid cavity, which presents with recurrent otorrhoea through a tympanic membrane, microorganisms can enter into the middle ear via the external ear canal. Infection of middle ear mucosa subsequently results in ear discharge [4].

CSOM is clinically distinguished into two main types, 1) tubotympanic (mucosal type / central tympanic perforation) involves the pars tensa, also called "safe" type as less likely to result in grave intracranial complications. 2) Squamosal or atticoantral type (attic or marginal perforation) involves pars flaccid, as squamous epithelium during the active phase of the disease erodes the bones in the middle ear, also known as "unsafe" type. Bone erosion, with potentially dangerous results, was an inherent pathological feature. Another synonym has been erosive middle ear disease and also called 'unsafe disease'. [1]. Chronic suppurative otitis media is well established in affecting the hearing ability of patients. Chronic suppurative otitis media, even though capable of both conductive and sensorineural hearing loss which accounts for most conductional deafness cases resulting in about $1.5 \%$ of speech disorders [3].
Causative microorganisms may be bacteria, fungi and viruses resulting in inflammation of the mucosal lining of the middle ear. If not treated it leads to partial or total loss of the tympanic membrane and ossicles resulting in acquired hearing loss [5]. Infection can spread from the middle ear to involve the mastoid, facial nerve, labyrinth, lateral sinus, meninges and brain leading to a mastoid abscess, facial nerve paralysis, deafness, lateral sinus thrombosis, meningitis and Intracranial abscess [6].

People coming from low socioeconomic status, spillover living spaces, no health coverage, emancipation and population explosion are at risk of disease and contribute to prevalence. It is the commonest children infectious disease worldwide starting early in life but in our environment; presentation may be in adult life [7]. Among SouthEast Asian countries, India has the highest prevalence rate of $7.8 \%$. [8] Over $50 \%$ of the cases are caused by bacteria [4]. In CSOM common aerobic bacteria are Pseudomonas, staphylococcus aureus, Escherichia coli, streptococcus pyogenes, Proteus mirabilis and Klebsiella spps [9]. and Anaerobic bacteria are Bacteroides, Peptostreptococcus and peptococcus etc., and the most common fungi are Aspergillus species and Candida species but the distribution of these isolates differ in various geographical areas.[4].

The diagnosis of chronic suppurative otitis media mainly relies on the clinical examination and the patient's history and is assisted by microbiological findings of the exudates sample and radiological findings of the temporal bone. Direct demonstration by staining methods (Gram staining) and bacteriological culture help in empirical treatment which is of immense help after the failure of tentative failure with local antibiotic therapy. CT scan is confined to extracranial complications, whereas MRI particularly delineates intracranial pathology and complicates Chronic suppurative otitis media.[10].

Topical preparations containing antibiotics and steroids, to reduce otorrhoea and to provide local anti-inflammatory effects are the basis of medical management of chronic suppurative otitis media. [3]. The knowledge of bacterial aetiology of CSOM is very important for the clinicians for appropriate management of the cases to prevent the emergence of resistant strains. [11]. The higher incidence of diseases like CSOM in nations other than developed countries is attributed to improper and irrational usage of antimicrobials. 
The present study was conducted to isolate aerobic bacteria involved in the Chronic suppurative otitis media and their antibiotic susceptibility pattern. A study of anaerobic bacteria causing CSOM and antibiotic susceptibility patterns was not included in this study.

\section{Methods}

This was a cross-sectional study performed in the Department of Microbiology, GSL Medical College and General Hospital, Rajamundry from May 2019 to October 2019. Ethical committee approval was obtained before starting the study. After obtaining written informed consent, a total of 135 patients clinically diagnosed with chronic suppurative otitis media presenting with more than 3 weeks of ear discharge and who did not receive any topical antibiotics in the past one week were included in the study. Detailed clinical history regarding name, age, sex, duration of discharge, other associated symptoms and antibiotic therapy were noted down. History was taken from patients.

\section{Inclusion criteria:}

01. All the patients were clinically diagnosed with CSOM.

02. All the patients having active purulent discharge during a clinical examination.

\section{Exclusion criteria:}

01. Cases with acute discharge (less than 3 weeks).

02. Cases of otits externa (intact tympanic membrane).

03. Patients with a history of receiving antibiotic treatment during the time of presentation (topical or systemic antimicrobials within the last 7 days).

04. Patients with cleft palate.

Sample size: Convenient sampling was done in 135 patients of Chronic suppurative otitis media attending GSL medical college and General Hospital, Rajamundry. During the study period of 6 months (May to October 2019).

The sample size was calculated using $n=4 p q / 12$.

Prevalence of CSOM is reported at $33 \%, q=67$.

An error was taken at $20 \%$.

By implementing these values our recommended sample size was 203 .
Methodology: Exudate sample from the affected ear was collected with the help of two sterile swabs. A smear was made on a glass slide for a direct demonstration from the 1st swab (Gram stain and ZN stain). The second swab was processed for the isolation of aerobic bacteria. The organisms were identified by morphology, culture characteristics, pigment production and biochemical reactions like Catalase, Oxidase test, Indole production, Methyl red test, Voges Proskauer test, Citrate utilization test, Urease Production test and Triple sugar Iron agar test, Oxidation/ fermentation for glucose, maltose, lactose, sucrose, xylose and mannitol (Hugh and Leifson's media), Lysine and Ornithine decarboxylase and Arginine dihydrolase activity, ONPG test, Esculin test etc were done for isolation of the Gram-negative and positive bacteria, followed by antibiotic sensitivity test $[12,13]$. The swab was subcultured on blood agar, Mac Conkey agar and chocolate agar and incubated aerobically at 37oC and evaluated regularly for 72 hours before discarding them. [14]. The isolated aerobic pathogens antibiogram was done by Kirby-Bauer disc diffusion method on Muller-Hinton agar as per CLSI guidelines.

Statistical analysis: Data analysis and statistical analysis was performed by using a statistical package for the social sciences (SPSS) software 27.0 and MS Microsoft excel 2007. Chi-square test was used to find the statistical significance, $p$-value $<0.05$ is considered to be statistically significant.

\section{Results}

A total of 135 clinically diagnosed Chronic suppurative otitis media patients attending GSL Medical College and General Hospital, Rajamundry during the study period were taken. Even though our recommended sample size was 203 due to the weather conditions and shorter study period, we opted for the convenient sampling, to get 135 participants. A total of 156 strains were isolated from 135 patients enrolled in the study. 87 (64\%) patients had a single organism (99 strains) isolated from middle ear culture while the remaining 22 (16.39\%) had 2 or more organisms (57 strains) isolated. 26 patients had a sterile culture with no organisms isolated (Table 1 ).

Table 1. Bacteriological culture results

\begin{tabular}{|l|l|l|}
\hline \multicolumn{1}{|c|}{ Culture Result } & \multicolumn{1}{|c|}{ Number } & \multicolumn{1}{c|}{ Percentage } \\
\hline Culture positive & 109 & $80 \%$ \\
\hline Sterile/ no growth & 26 & $19.5 \%$ \\
\hline
\end{tabular}


Pantagada N. et al: The Study of Bacteriological Agents of Chronic

Total samples

\begin{tabular}{|l|l|}
\hline 135 & $100 \%$ \\
\hline
\end{tabular}

Among 109 culture-positive patients 73(67\%) were male and $36(33 \%)$ were female (Table 2 ).

Table 2. Sex wise distribution

\begin{tabular}{|l|l|l|l|}
\hline \multicolumn{1}{|c|}{ Gender } & \multicolumn{1}{c|}{ Culture positive } & Culture negative & Total \\
\hline Male & 73 & 16 & 89 \\
\hline Female & 36 & 10 & 46 \\
\hline Total subjects & 109 & 26 & 135 \\
\hline $\begin{array}{l}\text { Chi square }=0.276 \\
\text { p value }=0.599 \\
\text { Not significant }\end{array}$ & & \\
\hline
\end{tabular}

The age of the subjects in the study group varies from $1 y r$ to 65 years. Maximum patients of Chronic suppurative otitis media belonged to age groups of $11-20$ years $38(35 \%)$ and the least cases was $8(7 \%)$ found in the age group of 41 to 50 years. (Table 3)

\section{Table 3. Age-wise distribution}

\begin{tabular}{|l|l|l|}
\hline \multicolumn{1}{|c|}{ Age Group } & \multicolumn{1}{c|}{ Number } & \multicolumn{1}{c|}{ Percentage } \\
\hline $0-10 \mathrm{yrs}$ & 30 & $27 \%$ \\
\hline $11-20 \mathrm{yrs}$ & 38 & $35 \%$ \\
\hline $20-30 \mathrm{yrs}$ & 13 & $12 \%$ \\
\hline $30-40 \mathrm{yrs}$ & 10 & $9 \%$ \\
\hline $40-50 \mathrm{yrs}$ & 08 & $7 \%$ \\
\hline$>50 \mathrm{yrs}$ & 10 & $9 \%$ \\
\hline Total & 109 & $100 \%$ \\
\hline
\end{tabular}

Out of 156 strains Pseudomonas was most commonly isolates $46(29 \%)$ followed by Staphylococcus aureus 43(27.5\%) and other organisms like Proteus species 19(12\%), coagulasenegative Staphylococci 15(9.6\%), Escherichia coli $10(6.41 \%)$, Klebsiella species 10(6.41\%), Citrobacter species 6(3.84\%), and Streptococcus pyogenes $3(1.92 \%)$. The least common was Enterococcus and Enterobacter spps 2(1.25\%). (Table 4).

\section{Table 4. Distribution of organisms}

\begin{tabular}{|l|l|l|}
\hline \multicolumn{1}{|c|}{ Type of Organisms } & \multicolumn{1}{|c|}{$\begin{array}{c}\text { Number of } \\
\text { Isolates }\end{array}$} & $\begin{array}{c}\text { Percentag } \\
\text { Pseudomonas aeruginosa }\end{array}$ \\
\hline Staphylococcus aureus & 46 & $29.4 \%$ \\
\hline Proteus spps & 43 & $27.5 \%$ \\
\hline Coagulase negative Staphylococci & 19 & $12 \%$ \\
\hline ConS) & 15 & $9.6 \%$ \\
\hline Escherichia coli & & $6.41 \%$ \\
\hline Klebsiella & 10 & $6.41 \%$ \\
\hline Citrobacter & 10 & $3.84 \%$ \\
\hline Streptococcus pyogenes & 6 & $1.92 \%$ \\
\hline Enterococcus spps & 3 & $1.28 \%$ \\
\hline
\end{tabular}

\begin{tabular}{|l|l|l|}
\hline Enterobacter spps & 2 & $1.28 \%$ \\
\hline
\end{tabular}

Gram-negative bacilli other than Pseudomonas showed maximum sensitivity to Imipenem (96\%) followed by Piperacillin (91\%), Levofloxacin (81\%), Amikacin (69\%) and Ampicillin (67\%). Lesser sensitivity was observed with Ceftazidime (64\%) Cefotaxime (62\%) and Ciprofloxacin (61\%) and the least sensitivity was seen to Cotrimoxazole (57\%) (Table 5).

\section{Table 5. Sensitivity Pattern of GNB other than Pseudomonas}

\begin{tabular}{|l|l|l|}
\hline \multicolumn{1}{|c|}{ Antibiotic } & Number of Isolates Sensitive & Percentage \\
\hline Amikacin & 32 & $69 \%$ \\
\hline Ampicillin & 31 & $67 \%$ \\
\hline Cotrimoxazole & 27 & $57 \%$ \\
\hline Ceftaxime & 29 & $62 \%$ \\
\hline Ceftazidime & 30 & $64 \%$ \\
\hline Ciprofloxacin & 28 & $61 \%$ \\
\hline Levofloxacin & 38 & $81 \%$ \\
\hline Imipenem & 45 & $96 \%$ \\
\hline Piperacillin & 42 & $91 \%$ \\
\hline
\end{tabular}

Sensitivity pattern for Pseudomonas aeruginosa maximum isolates sensitive to Imipenem (95\%), Levofloxacillin (89\%) and Piperacillin (81\%). Fairly sensitive to Polymyxin B (77\%), Celestin (76\%) and Gentamycin (67\%) and least sensitive to Ceftazidime (61\%) and Amikacin (63\%) (Table 6).

Table 6. Sensitivity Pattern of Pseudomonas

\begin{tabular}{|l|l|l|}
\hline \multicolumn{1}{|c|}{ Antibiotic } & Number of Isolates Sensitive & Percentage \\
\hline Amikacin & 29 & $63 \%$ \\
\hline Ceftazidime & 28 & $61 \%$ \\
\hline Celestin & 35 & $76 \%$ \\
\hline Polymixixn B & 36 & $77 \%$ \\
\hline Gentamycin & 30 & $67 \%$ \\
\hline Levofloxacin & 37 & $81 \%$ \\
\hline Imipenem & 40 & $89 \%$ \\
\hline Piperacillin & 43 & $95 \%$ \\
\hline
\end{tabular}

Gram-Positive cocci were maximum sensitive to Lenizolid followed by Ciprofloxacin (82\%) and Cloxacillin (79\%), less sensitive to Vancomycin (73\%), Tetracycline (71\%) and Cephalexin (70\%) and least sensitive to cotrimoxazole (63\%), Erythromycin (52\%) and Ampicillin (42\%). Isolation and antibiotic sensitivity of Anaerobes is not included in this study (Table 7).

Table 7. Sensitivity Pattern of Gram Positive COCCI

\begin{tabular}{|l|l|l|}
\hline Antibiotic & Number of Isolates Sensitive & Percentage \\
\hline Ampicillin & 26 & $42 \%$ \\
\hline
\end{tabular}




\begin{tabular}{|l|l|l|}
\hline Cloxacillin & 50 & $79 \%$ \\
\hline Erythromycin & 33 & $52 \%$ \\
\hline Tetracycline & 45 & $71 \%$ \\
\hline Cotrimoxazole & 40 & $63 \%$ \\
\hline Ciprofloxacin & 52 & $82 \%$ \\
\hline Cephalexin & 44 & $70 \%$ \\
\hline Vancomycin & 46 & $73 \%$ \\
\hline Linezolid & 57 & $91 \%$ \\
\hline
\end{tabular}

\section{Discussion}

Chronic suppurative otitis media is one of the common ear infections which are more reported from rural populations and lower socioeconomic status groups.[7]. It is a chronic infection of the middle ear that can lead to deafness. Poorly treated or untreated Chronic suppurative otitis media can lead to many complications like mastoiditis, meningitis and brain abscess. Chronic suppurative otitis media and various complications associated with the disease such as irreversible local destruction of middle ear structure facial palsy, serious intracranial and extracranial complication are also seen by clinicians. Early microbiological diagnosis ensures prompt and effective treatment to avoid such complications.[9]. This study was conducted for the assessment of the aerobic bacteriological profile of Chronic suppurative otitis media, and their antibiogram pattern. The results were compared with the other studies and discussed as follows.

In this research, the rate of infectivity was more among males compared to females i.e., males 73 $(67 \%)$ and females $36(33 \%)$. This finding aligns with the study conducted by Vikas Jain et al [4]. who showed $58.65 \%$ male and $55 \%$ female cases, Ahmed et al [16]. 57.29\% Male and $42.7 \%$ female and Sahu et al [17]. (Male 58\% and Female 42\%). But differs from Jitendra et al [1]. (Female $64 \%$ \& male $36 \%$ ) Naz R et al [7]. (53\% female and $47 \%$ male) and Shreshta et al [18]. (55.2\% female and $44 \%$ male). In the present study the age ranged from less than one year to more than $50 y$ rs.

In this study the peak incidence of Chronic suppurative otitis media was found in the age group of $11-20 y$ rs $38(35 \%)$ followed by $0-10 y$ rs $30(27 \%)$. These findings were correlated with studies of Vikas Jain et al (4), Rangaiah et al (8), Naz R et al [7], Ashutosh Rawat et al [19]. and OV Akinpelu et al [20]. (1stand 2nd decade). Possible reason being the frequent upper respiratory infections seen in this age group due to Eustachian tube dysfunction.
The most common organism isolated in the present study was Pseudomonas aeruginosa 46 (29\%) followed by Staphylococcus aureus $43(27.5 \%)$. These findings were inconsistent with the studies of Jitendra et al, (1) Vikas Jain et al (4), Hiremath et al [21]. and Loy et al [22]. But differs from Naz R et al (7) and Rangaiah ST et al (8) where the most common microorganism is Staphylococcus aureus followed by Pseudomonas. The predominance of Pseudomonas aeruginosa as the major isolate in CSOM could be because of its characteristic features like ubiquitous nature, minimal nutritional requirement and inherent persistence to major antibiotics.

The frequency of the Staphylococcus aureus in the middle ear infections can be attributed to their ubiquitous nature and high carriage of resistant strains in the external auditory canal and upper respiratory tract. $[17,18]$. The other pathogens isolated were Klebsiella spps, Proteus spps, Escherichia coli, Citrobacter and Enterobacter spps. This is similar to studies of $\mathrm{Naz} \mathrm{R}$ et al, [7] Gopichand et al [23]. and Swayamsidha Andhale et al. [24]. The pathogens such as Pseudomonas spp., Proteus spp. are opportunistic organisms that may penetrate to the middle ear through the external auditory canal. In this process, they may damage the tympanic membrane leading to otitis media. Organisms like E. coli and Klebsiella spp. Become opportunistic pathogens in the middle ear when resistance is low. [23].

A study by Prakash et al [25]. found significant proportions of anaerobes (29.41\%) Predominantly Clostridium spps, Peptococuss and Peptostreptococuss studies by Rangaiah ST et al (8) and Maji et al (26) showed no and negligible anaerobes isolation. In this study no anaerobes were isolated. Antibiotic susceptibility testing was carried out for all the microorganisms isolated. Most of the isolates were found to be sensitive to Imipenem and Staphylococcus aureus isolates were most sensitive to Linezolid, similar to the studies of Naz R et al (7) and Rangaiah ST et al, (8) Singh et al. [27] Most of the studies showed maximum susceptibility of culture isolates to Amikacin, Ceftazidime and Gentamycin. [4,25]. In this research most of the isolates were resistant to penicillin and cephalosporins, cell wall inhibitors. Currently drug resistance is one of the alarming threats in medicine. Indiscriminate usage of antibiotics and incomplete dosage are the contributing factors for this drug resistance. 
Usually in the developing countries the patients stop taking the medication once the symptoms were relieved. (7) This is one of the significant hurdles which has been overcoming through counselling. In this study despite these efforts drug resistance was identified to be significant. (Table 5,6 \& 7)

Though ciprofloxacin is non- ototoxic, widespread usage of it, is the main cause of increased resistance by quinolones against the isolates. According to the declining sensitivity may be due to several factors including injudicious use, inappropriate dosage, and easy accessibility and developing enzymatic resistance of organisms against quinolones.[7].

\section{Conclusion}

Chronic suppurative otitis media is a disorder of the ear that persists for a long time can lead to hearing loss, developmental disabilities which eventually leads to limit day-to-day activities and standard of living. Continous ear discharge in an active Chronic suppurative otitis media needs to be treated diligently according to the antibiotic susceptibility pattern of causative organisms. The purpose of continuing medical therapy for Chronic suppurative otitis media would be to prepare the ear by reducing the bacterial load before surgery and improving the graft uptake and stability of middle ear function post-surgery.

The present study is taken up with an aim of isolation and identification of etiological pathogens of CSOM, especially with irrational usage of antimicrobial drugs nowadays. To summarize the results of the present research, it is highly suggested to have a clear diagnosis of the causative organisms and their antimicrobial susceptibility pattern to treat CSOM and reduce further complications.

It can be concluded that in this study males are more commonly affected than females, Chronic suppurative otitis media is common in the early decades of life and a variety of bacteria are responsible for chronic suppurative otitis media with the predominance of Pseudomonas and Staphylococcus aureus followed by Proteus, Coagulase Negative Staphylococci, Klebsiella and Escherichia coli, Citrobacter, Streptococcus pyogenes, Enterococcus, Enterobacter spps. Our study showed that the isolates were sensitive to higher antibiotics like Imipenem, Piperacillin and Quinolones.
Hence it is suggested to have proper information of antibiogram of causative microorganisms can aid inappropriate usage of antibiotics and they're by the successful outcome of CSOM. Establishing institutional antibiotic policy, efficient antibiotic stewardship programme in lieu with infection control committee, vigilance over the antibiotics sold over the counter and reduction in improper usage by quackery may further reduce the incidence of CSOM.

\section{Authors contributions}

Dr. Neelima Pantagada: data collection and analysis, manuscript preparation, bench work.

Dr. Praveen Kavoori: literature search, statistical analysis.

\section{What this study adds to existing knowledge}

Chronic suppurative otitis media patients, Pseudomonas and Staphylococcus were highly prevalent and showed increased resistance to betalactams and commonly used antimicrobial drugs.

\section{Reference}

01. Jitendra and Shiv Kumar. Microbiological profile and Antibiogram in cases of Chronic suppurative otitis media at a Tertiary care Hospital, Jaipur. Int J Curr Microbiol App Sci. 2018;7(01):395-407. doi: 10.20546/ijcmas.2018.701.045 [Crossref][PubMed] [Google Scholar]

02. Klein, Jerome O. Otitis externa, otitis media, and mastoiditis. Mandell, Douglas, and Bennett's principles and practice of infectious diseases. (2015): 767. [Crossref][PubMed][Google Scholar]

03. Dhingra BC, Dhingra S. Diseases of the ear, nose and throat, 5thed. New Delhi: Elsevier. 2010;75-83. [Crossref][PubMed][Google Scholar]

04. Vikas J, Swathi J. Bacteriological profile of Chronic suppurative otitis media and Antibiotic Sensitivity Pattern of Aerobic isolates in $\mathrm{TCH}$ of Central India. Int $\mathrm{J}$ Curr Microbiol App Sci. 2019:8(01):2240-46. DOI: 10.20546/ijcmas.2019.801.234 [Crossref][PubMed] [Google Scholar] 
05. Kumar R, Srivastava $P$, Sharma M, Rishi $S$, Nirwan $S$, Hemwaniand $K$. Isolation and antimicrobial sensitivity profile of bacterial agents in chronic suppurative otitis media patients at NIMS Hospital, Jaipur. IJPBS. 3;4(2013):265-9. [Crossref] [PubMed][Google Scholar]

06. Kumar S, Sharma R, Saxena A, Pandey A, Gautam P, Taneja V. Bacterial flora of infected unsafe CSOM. Indian journal of Otology. 18;4(2012):208. [Crossref][PubMed][Google Scholar]

07. Naz R, Farooqui M K, Girotra R, Yadav M, et al. A Bacterial profile and antibiotic sensitivity pattern of CSOM patient in Mewat region. J Evid Based Med Health. 2;61(2015):9051-54. [Crossref][PubMed] [Google Scholar]

08. Sowmya TR, Ravi D, M Hanumanth P. Bacteriological Profile of Chronic suppurative otitis media in $\mathrm{TCH}$. Int J Otorhinolaryngology Head Neck Surg. 2017;3:601-5. [Crossref][PubMed][Google Scholar]

09. WHO. State of Hearing and Ear care in SEA region. WHO Regional office for SEA. [Crossref] [PubMed][Google Scholar]

10. Jung TT, Hanson JB. Classification of otitis media and surgical principles. Otolaryngol Clin North Am. 1999 Jun;32(3):369-83. doi: 10.1016/s00306665(05)70139-0 [Crossref][PubMed][Google Scholar]

11. Prakash M, Lakshmi K, Anuradha S, Swathi G N. Bacteriological profile and their antibiotic susceptibility pattern of cases of chronic suppurative otitis media. Asian journal of Pharmaceutical and clinical research. (2013):210-212. [Crossref] [PubMed][Google Scholar]

12. Betty A Fobes, Daniel F Sahm, Alice Weissfields. Bailey \& Scott Diagnostic Microbiology, 12th Edition. Elsevier. 2007:832-42. [Crossref][PubMed][Google Scholar]

13. Duguid JP, Coll JG, Fraser AG. Laboratory Strategy in the diagnosis of infective syndrome In: Mackies \& McCartney Practical Medical Microbiology (14 Edition). Churchill Livingstone, London. 2004. [Crossref][PubMed][Google Scholar]

14. Elmer $W \mathrm{~K}$, et al. A Color Atlas and Text Book of Diagnostic Microbiology. . (1997):122-30. [Crossref] [PubMed][Google Scholar]
15. Clinical \& Laboratory Standard Institute. 2012 Performance Standards for Antimicrobial Susceptibility Testing. Clinical \& Laboratory Standards Institute. Wayne. 24th Informational supplement [Crossref][PubMed][Google Scholar]

16. Ahmed, Ashfaq, Javaid Usman, and Rizwan Hashim. Isolates from chronic suppurative otitis media and their antimicrobial sensitivity. Pak Armed Forces Med J. 49;2(1999):82-5. [Crossref][PubMed] [Google Scholar]

17. Susmita Kumari Sahu, Moningi Venkata Narasimham, Indrani. Microbiological Profile of Chronic suppurative otitis media \& InVitro ASP in a $\mathrm{TCH}$. Otolaryngology Online Journal. 2014;4(4). [Crossref][PubMed][Google Scholar]

18. Shrestha B L, Amatya R C M, Shrestha I, Ghosh I. Microbiological profile of chronic supurative otitis media. Nepalese Journal of ENT Head and Neck Surgery. 2;2(2011):6-7. [Crossref][PubMed][Google Scholar]

19. Ashutosh Rawat, Roma Goyal. A Study of Bacterial Profile and Antibiotic Susceptibility Pattern of CSOM. Intrernational Journal of Microbiolgy Applied Science. 2015;4(8): 3-27. [Crossref] [PubMed][Google Scholar]

20. Akinpelu OV, Amusa YB, Komolafe EO, Adeolu $A A$, Oladele AO, Ameye SA. Challenges in management of chronic suppurative otitis media in a developing country. J Laryngol Otol. 2008 Jan;122(1):16-20. doi: 10.1017/S0022215107008377 [Crossref][PubMed] [Google Scholar]

21. Hiremath S L, Kanta R C, Yeshwanathrao M, Vasantha Kumar C M. Aerobic bacterial isolates of CSOM and their antibiotic sensitivity pattern. The Indian Practitioner. 54;7(2001): 486-489. [Crossref] [PubMed][Google Scholar]

22. Loy $A H$, Tan AL, Lu PK. Microbiology of chronic suppurative otitis media in Singapore. Singapore Med J. 2002 Jun;43(6):296-9. [Crossref][PubMed] [Google Scholar]

23. Wadile Rahul Gopichand, Bhate Viraj Madues. Bacteriological Profile of Chronic suppurative otitis media. Int Journal Current Applied Sciences. 2015;4(6):41-47. Scholar] 
24. Swayamsidha Andhale, Parag Swanth, Goel HC. Microbiology of Chronic suppurative otitis media without cholesteatoma. Goa National Journal of Otolaryngology and Head and Neck Surgery. April 2015;3(12):no 1. [Crossref][PubMed][Google Scholar]

25. Prakash R, Juyal D, Negi V, Pal S, Adekhandi S, Sharma $M$, et al. Microbiology of chronic suppurative otitis media in a tertiary care setup of uttarakhand state, India. N Am J Med Sci. 2013 Apr;5(4):282-7. doi: 10.4103/1947-2714.110436 [Crossref] [PubMed][Google Scholar]
26. Maji PK, Chatterjee TK, Chatterjee S, Chakrabarty J, Mukhopadhyay BB. The investigation of bacteriology of chronic suppurative otitis media in patients attending a tertiary care hospital with special emphasis on seasonal variation. Indian J Otolaryngol Head Neck Surg. 2007 Jun;59(2):12831. doi: 10.1007/s12070-007-0038-x [Crossref] [PubMed][Google Scholar]

27. Singh A H, R Basu, and A Venkatesh. Aerobic bacteriology of chronic suppurative otitis media in Rajahmundry, Andhra Pradesh, India. Biology and Medicine. 4;2(2012):73. [Crossref][PubMed][Google Scholar] 